\title{
Typh fevers: a combination of Typhoid and Typhus
}

\author{
Robin George Manappallil \\ Consultant, Department of Internal Medicine, Baby Memorial Hospital, Calicut, Kerala 673004, India
}

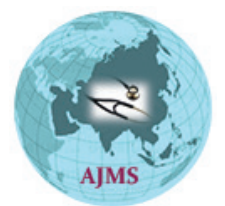

\section{A B S TR A C T}

Typhoid fever is caused by Salmonella typhi, while typhus fever is a rickettsial infection. In both cases the patients present with almost similar pattern of illness and are often misdiagnosed. This is the case of a young lady who presented with 10 days history of fever and was diagnosed to have typhoid fever. She continued to be febrile despite ceftriaxone therapy. She was later found to have a typhus coinfection and improved with addition of doxycycline.

Key words: Typhoid, Typhus, Weil Felix test, Thrombocytopenia
Access this article online

Website:

http://nepjol.info/index.php/AJMS

DOI: 10.3126/ajms.v8i6.18270

E-ISSN: 2091-0576

P-ISSN: 2467-9100

\section{INTRODUCTION}

Enteric fevers include typhoid and paratyphoid fevers which are caused by Salmonella typhi and Salmonella paratyphi (A and B) respectively. They are Gram negative bacilli and are transmitted by faecal-oral route by carriers. ${ }^{1}$ Typhus fevers are a group of rickettsial diseases, which include epidemic typhus, murine typhus and scrub typhus. Epidemic typhus is caused by Rickettsia prowazekii and spread by body lice. Murine typhus due to Rickettsia typhi and scrub typhus by Orientia tsutsugamushi are transmitted by fleas and chiggers respectively. ${ }^{2}$ Epidemic typhus may be misdiagnosed as typhoid fever or its co-infection with typhoid may be overlooked because of the similarities in presentation.

\section{CASE REPORT}

A 30 year old female, housewife, presented to Medicine OPD with 10 days history of fever and myalgia. She had 2-3 episodes of loose stools initially. There was no history of malena or skin rash. She was not a known case of any comorbid condition. She had consulted a local practioner and had taken amoxicillin with clavulanic acid (625mg twice daily) for 5 days; but there was no relief of symptoms. On examination, she was conscious, oriented and febrile $\left(102^{\circ} \mathrm{F}\right)$. Her pulse rate was $80 /$ minute (regular), blood pressure $110 / 80 \mathrm{mmHg}$, respiratory rate $22 /$ minute with saturation $96 \%$ in room. She was not icteric. Her systemic examinations were normal. Her blood investigations showed leucopenia (3200 cells/cmm with N80 L19 E1), thrombocytopenia
(120,000 cells/cmm) and mildly elevated liver enzymes (SGOT 65 U/L, SGPT 79 U/L). Other blood investigations like renal parameters, bilirubin, electrolytes, PT/INR and aPT'T were normal. Urine routine did not show any pus cells. Smear for malarial parasite, dengue and leptospira serology, Mantoux test and viral markers (HIV, HBsAg, anti HCV) were negative. Ultrasound abdomen, ECG and chest Xray were normal. In view of her symptoms and relative bradycardia, a provisional diagnosis of enteric fever was considered. She was started on intravenous ceftriaxone (2 gram/day). Her blood culture grew Salmonella typhi (which was sensitive to ceftriaxone). Despite 4 days of ceftriaxone, continued to have fever spikes of $100^{\circ} \mathrm{F}$. Weil Felix test showed 1:320 titres for OX19 antigen, suggestive of typhus infection. Serology for scrub typhus was negative. Oral doxycycline $(100 \mathrm{mg}$ twice daily) was added along with ceftriaxone. The following day, she became afebrile. Her thrombocytopenia and liver enzymes started normalizing. She was given ceftriaxone and doxycycline for total of 10 days and was discharged with normal blood counts and liver functions.

\section{DISCUSSION}

Typhoid fever is characterised by prolonged fever associated with headache, chills, cough, sweating, arthralgia, myalgia and malaise. The fever may last for 4-8 weeks in untreated patients. Abdominal complaints include bowel disturbances (constipation or diarrhoea) with mild tender hepatomegaly. Relative bradycardia is an important sign. The characteristic "rose spots" are seen over the chest and abdomen at the 
end of first week of illness and disappear in 2-5 days. By the end of second week, patients become toxic and by the third week they may pass into coma and die. Blood investigations usually show leucopenia, neutropenia and moderately elevated liver enzymes. The definitive diagnosis is made by isolation of the bacilli from blood, bone marrow, rose spots, stool or intestinal secretions. Widal tests have a lower positive predictive value than blood culture. Ceftriaxone, cefotaxime, cefixime, azithromycin, chloramphenicol, ciprofloxacin and cotrimoxazole are the drugs of choice. Vaccines like Ty21a (oral live attenuated) and ViCPS (parenteral) are commercially available for prevention. ${ }^{1}$

Typhus fevers caused by rickettsial organisms include epidemic typhus, murine typhus and scrub typhus. Among these, epidemic typhus is sometimes misdiagnosed as typhoid fever. Fever, headache, rash (maculopapular, eschar) and myalgia are the common manifestations. Blood investigations show anaemia, leucopenia, thrombocytopenia, elevated liver enzymes and electrolyte imbalance. Serological and immunohistochemical tests are not widely available. Doxycycline is the drug of choice; chloramphenicol, azithromycin and ciprofloxacin are other alternatives. ${ }^{2}$

Weil Felix test is based on the detection of antibody to various Proteus antigens that cross-react with rickettsiae. These antigens include Proteus vulgaris OX2, P. vulgaris OX19 and P. mirabilis OXK. Although it lacks sensitivity and specificity, it may be used as first diagnostic step in diagnosis of rickettsial fevers. ${ }^{3}$ Cross-reactivity among the pathogen antigens is a major limitation. ${ }^{4}$ Positive titres for OX2, OX19 and OXK are suggestive of spotted fever group, typhus group and scrub typhus respectively. Clinical findings along with titres of 1:80 are considered positive. The test can detect IgM antibody 5-10 days following the onset of symptoms. ${ }^{5}$

There have been reports of typhoid coinfection with dengue, malaria, leptospirosis and hepatitis $\mathrm{A}$ and $\mathrm{E} \cdot{ }^{6-10} \mathrm{~A}$ coinfection of dengue and leptospirosis with scrub typhus have also been reported. ${ }^{11,12}$ With respect to typhoid coinfection with typhus fevers, less than a handful of cases have been reported. ${ }^{13-15}$

\section{CONCLUSION}

Typhus fevers like epidemic and murine typhus may sometimes be misdiagnosed as typhoid fever in tropical regions. Moreover, because of the clinical and laboratory similarities, a coinfection of typhoid with typhus fever can be overlooked. This case, therefore, emphasises the importance of screening patients with typhoid fever for rickettsial diseases, especially when patients do not respond to standard typhoid treatment.

\section{REFERENCES}

1. Pegues DA, Miller SI. Salmonellosis. In: Kasper, Fauci, Hauser, Longo, Jameson, Loscalzo (ed). Harrison's Principles of Internal Medicine. 19 ${ }^{\text {th }}$ ed. McGraw Hill education. pp. 1049-1053.

2. Walker DH, Dumler JS and Marrie T. Diseases caused by rickettsiae, mycoplasmas, and chlamydiae. In: Kasper, Fauci, Hauser, Longo, Jameson, Loscalzo (ed). Harrison's Principles of Internal Medicine. $19^{\text {th }}$ ed. McGraw Hill education. pp. 1158-1159.

3. Isaac R, Varghese GM, Mathai E, Manjula J and Joseph I. Scrub typhus: prevalence and diagnostic issues in rural southern India. Clin Infect Dis 2004; 39:1395-1396.

4. Parola P and Raoult D. Ticks and tickborne bacterial diseases in humans: an emerging infectious threat. Clin Infect Dis 2001; 32:897-928.

5. Mittal V, Gupta N, Bhattacharya D, Kumar K, Ichhpujani RL, Singh S, et al. Serological evidence of rickettsial infections in Delhi. Indian J Med Res 2012; 135(4): 538-541.

6. Vigna SRV, Gopalsamy S and Srikanth P. Dengue and typhoid co-infection: A case report from a tertiary care hospital in South India. Int J Case Rep Images 2016; 7(10):563-565.

7. Bansal $R$, Bansal $P$ and Tomar LR. Typhoid and dengue coinfection: case reports. Trop Doct 2015; 45(1):52-53.

8. Birhanie M, Tessema B, Ferede G, Endris M and Enawgaw B. Malaria, Typhoid Fever, and Their Coinfection among Febrile Patients at a Rural Health Center in Northwest Ethiopia: A CrossSectional Study. Advances in Medicine, vol. 2014, Article ID 531074, 8 pages, 2014.

9. Anupriya A, Meera J and Uma A. Dual Edge Sword- Leptospirosis and Typhoid Coinfection with Rare Complications- A Case Report. Sch J Med Case Rep 2016; 4(5):363-365.

10. Bhat D, Dhooria GS and Bains HS. Coinfection of Hepatitis A and $E$ with Salmonella Infection; a Case Report. Iran J Pediatr 2009; 19(1):79-81.

11. Sapkota S, Bhandari S, Sapkota S and Hamal R. Dengue and Scrub Typhus Coinfection in a Patient Presenting with Febrile Illness. Case Reports in Infectious Diseases 2017; 2017:6214083.

12. Ho YH, Chen LK, Tsai PJ and Wang LS. Coinfection with Leptospirosis and Scrub Typhus- A Report of Four Cases. Tzu Chi Med J 2006; 18:237-240.

13. Mazumder RN, Pietroni MA, Mosabbir N and Salam MA. Typhus fever: an overlooked diagnosis. J Health Popul Nutr 2009; 27:419-421.

14. Basak $R$ and Islam N. Typhus fever: an uncommon childhood infection-report of a case from northern region of Bangladesh. Chattagram Maa-O-Shishu Hosp Med Coll J 2013; 12(2):49-51.

15. Seow CW-X, Logarajah $\mathrm{V}$ and Tan NWH. Typhoid and Scrub Typhus Coinfection in a Returned Traveler. Global Pediatric Health 2017; 4:2333794X17726941.

\footnotetext{
Authors Contribution:

RGM- Concept and design of case report, reviewed the literature, manuscript preparation, critical revision of the manuscript and treating physician.

Orcid ID:

Dr. Robin George Manappallil : (i) http://orcid.org/0000-0003-3973-6800

Source of Support: None, Conflict of Interest: None.
} 